\title{
Mapeamento do Risco de Incêndios Florestais Utilizando Técnicas de Geoprocessamento
}

\author{
Fillipe Tamiozzo Pereira Torres ${ }^{1}$, Mariane Paulina Batalha Roque ${ }^{1}$, \\ Gumercindo Souza Lima ${ }^{1}$, Sebastião Venâncio Martins ${ }^{1}$, \\ André Luiz Lopes de Faria ${ }^{1}$ \\ ${ }^{1}$ Universidade Federal de Viçosa - UFV, Viçosa/MG, Brasil
}

\begin{abstract}
RESUMO
O objetivo deste estudo foi definir, através da análise da influência de fatores preditores como clima, relevo, uso do solo e influência antrópica, um mapa de risco de incêndios florestais com a utilização de técnicas de geoprocessamento. De acordo com os resultados, nenhuma das classes preditoras explicou, de forma isolada, a espacialização das ocorrências. Todavia este estudo conseguiu retratar a influência dos fatores sobre as ocorrências de incêndios florestais. Os mapas gerados apresentaram satisfatória eficiência na predição de incêndios na região de estudo.
\end{abstract}

Palavras-chave: fogo, mapa, SIG.

\section{Mapping of Forest Fires Risk Using Geoprocessing Techniques}

\begin{abstract}
This study aimed to define, by analyzing the influence of predictive factors like climate, topography, land use and human influence, a risk map to forest fires with the use of GIS techniques. According to the results, none of the predictors' classes alone explains the spatial distribution of the occurrences. However, this study was able to show the influence of factors on the occurrence of forest fires. The generated maps show satisfactory efficiency in fire prediction in the study region.
\end{abstract}

Keywords: fire, map, GIS. 


\section{INTRODUÇÃO}

Os ecossistemas "naturais", através dos anos de interações com a espécie humana, sofreram alterações que culminaram com a elaboração da presente distribuição das formações vegetais (Ferreira et al., 2015). Para os autores, a introdução de plantações florestais uniformes e inflamáveis, êxodo rural e aumento das áreas degradadas e de pastagem aumentaram a homogeneidade da paisagem, levando a uma ampliação da susceptibilidade à ocorrência de incêndios.

Segundo Herawati \& Santoso (2011), os incêndios florestais geram problemas em diversas escalas. Localmente, promovem a degradação da vegetação, impactos sobre a biodiversidade, prejuízos financeiros e até mesmo perda de vidas. Regionalmente, entre outros, sua fumaça gera problemas para a saúde humana e afeta os meios de transporte. Em escala global, promovem aumento nas emissões de carbono para a atmosfera, podendo ter consequências para o clima planetário.

As características dos incêndios são afetadas pelas complexas interações entre vegetação, clima, topografia e atividades antrópicas ao longo do tempo. Em escala regional, o clima, por determinar o teor de umidade do combustível e a quantidade de biomassa, é o principal controlador das características dominantes dos incêndios, bem como do tipo de vegetação encontrado. Além disso, uso do solo e topografia afetam a frequência, velocidade de propagação e tamanho das áreas queimadas. Por outro lado, as atividades humanas têm influências dramáticas sobre as características dos incêndios, também alterando frequência, área queimada e padrão de distribuição das ocorrências (Chang et al., 2015). Por conta dessas observações, para Linn et al. (2012), a modelagem de incêndios florestais é difícil porque o comportamento do fogo é determinado por um conjunto extremamente complexo de processos acoplados, que ocorrem ao longo de um vasto leque de escalas espaciais e temporais. Corroborando, para Barlow et al. (2012), a previsão do risco de incêndio pode ser muito complicada, pois é dependente de interações entre fatores antrópicos e ambientais.

Contudo, as formas mais eficientes de prevenção começam a partir do conhecimento sobre o risco, o que permite o correto planejamento e alocação de recursos para seu combate (Borges et al., 2011).
De acordo com Fernandes et al. (2011), diversos autores apresentam a utilização do geoprocessamento como alternativa metodológica para o desenvolvimento de estudos que buscam o entendimento da estrutura, da função e da dinâmica dos elementos da paisagem a fim de definir a espacialização de fenômenos como o risco aos incêndios.

Para Pezzopane et al. (2001), os atuais recursos computacionais facilitam bastante os estudos temporais e espaciais de previsão e combate aos incêndios. A detecção de locais de maior risco pode ser viabilizada com o uso de um Sistema de Informações Geográficas (SIG).

Um SIG proporciona a capacidade de coletar, sobrepor, manipular e visualizar um grande volume de dados, que podem ser derivados a partir da análise da possibilidade de ignição de um incêndio florestal, do seu potencial de propagação e dos efeitos relacionados. Ele pode ser uma ferramenta para a coordenação de todos os envolvidos que devem tomar as medidas necessárias para a defesa contra os impactos relacionados a incêndios, e também especificar o local, o momento e o modo de realização dessas medidas (Vakalis et al., 2004).

Paz et al. (2011) argumentam que os mapas de risco de incêndio originados a partir de um SIG permitem aos gestores florestais planejar estrategicamente as atividades de prevenção a longo prazo.

Para Yang et al. (2007), as informações sobre a distribuição espacial dos incêndios florestais são necessárias para melhorar as estratégias de prevenção. A análise espacial das ocorrências pode fornecer novas informações para orientação dos esforços de planejamento e redução do risco.

Vijayakumar et al. (2015) ressaltam também a importância do alongamento dos registros históricos e mapas de ocorrência de incêndios a fim de proporcionar uma melhor perspectiva sobre as mudanças reais no seu comportamento e para compreender melhor a relação entre fogo e clima.

As potenciais diferenças no comportamento do fogo, entre regiões diferentes, precisam ser consideradas quando do planejamento otimizado e adoção de medidas geograficamente específicas de prevenção de incêndios (Zumbrunnen et al., 2011). Assim, o objetivo deste estudo foi definir a influência dos principais fatores preditores, confeccionar um mapa de risco para o município de Viçosa (MG) para subsidiar os processos 
de planejamento e gestão, bem como determinar a metodologia mais eficiente para o mapeamento do risco de incêndios na região.

\section{METODOLOGIA}

O estudo foi realizado no município de Viçosa, Minas Gerais $\left(20^{\circ} 45^{\prime} \mathrm{S}\right.$ e $\left.42^{\circ} 51^{\prime} \mathrm{W}\right)$. O clima na região é do tipo Cwb (Köppen), mesotérmico com verões quentes e chuvosos e invernos frios e secos (Miranda et al., 2012). A região caracteriza-se por uma topografia fortemente acidentada, apresentando porções reduzidas de área plana. A cobertura vegetal nativa pertence ao Domínio da Floresta Atlântica (Costa et al., 2013).

A elaboração do cartograma de risco de incêndios foi feita a partir do software ArcGIS 10.1, com a geração dos mapas de declividade, exposição das vertentes e de uso e ocupação do solo. Esses mapas foram intercruzados, possibilitando a determinação das áreas mais suscetíveis a incêndios.

O Modelo Digital de Elevação (MDE) (Figura 1A) foi elaborado a partir de dados altimétricos da
SRTM (Shuttle Radar Topographic Mission), com resolução espacial de aproximadamente $90 \mathrm{~m}, 16$ bits, disponibilizados pela National Aeronautics and Space Administration (NASA, 2010), que posteriormente foram convertidos, através do ArcGIS 10.1. Houve uma melhoria da resolução espacial a partir do refinamento de $90 \mathrm{~m}$ para $30 \mathrm{~m}$ pelo tratamento geoestatístico por krigagem. A partir dele foram gerados os cartogramas de declividade (Figura 1B) e exposição das vertentes (Figura 1C).

Já o mapa de uso e ocupação do solo (Figura 1D) foi originado através da interpretação visual das imagens Landsat, quando foram vetorizadas as seguintes classes: mata, capoeira, pastagem, reflorestamento, agricultura, solo exposto, corpos hídricos e área construída.

Os modelos de risco de incêndio descrevem e preveem a distribuição dos eventos. O fogo é um fenômeno complexo e é, portanto, razoável que a modelagem de risco de incêndios tenha uma estrutura complexa que represente os muitos fatores que afetam a ignição e propagação dessas ocorrências. Os modelos numéricos e computacionais são muitas vezes os

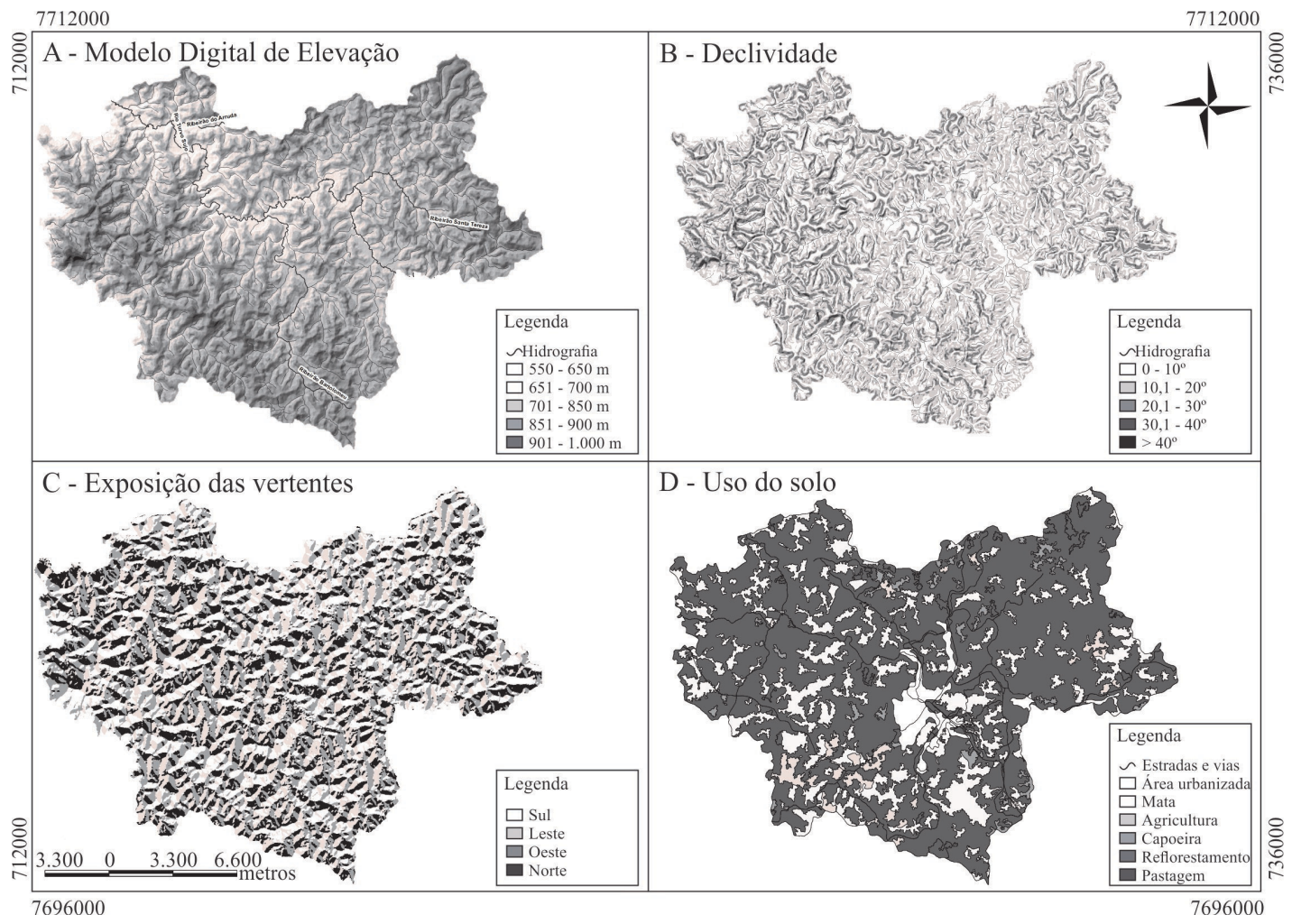

Figura 1. Cartogramas utilizados para a geração do cartograma de susceptibilidade a incêndios em Viçosa, MG. Figure 1. Cartograms used to generate the cartogram of fire's susceptibility in Viçosa (MG). 
únicos meios científicos para se compreender e prever fenômenos ambientais complexos e não lineares. Para efeitos de previsão, produzir um mapa de risco não é suficiente, sendo crucial se ter uma estimativa do grau de confiabilidade nos resultados do modelo. A validação é uma tentativa de aumentar o grau de confiança de que os eventos inferidos por um modelo irão, de fato, ocorrer nas condições assumidas (Paz et al., 2011). Para efeito de validação, neste estudo foram utilizados 79 focos de calor, observados entre 1/1/2005 e 31/12/2014, provenientes do sistema de detecção do INPE/CPTEC (Instituto Nacional de Pesquisas Espaciais/Centro de Previsão de Tempo e Estudos Climáticos). Para compor a série temporal analisada neste estudo foram utilizados os dados provenientes dos satélites de referência: o NOAA-12 até agosto de 2007 e, a partir dessa data, o AQUA_M-T (INPE, 2015).

Diante disso, foram gerados quatro cartogramas de risco de incêndios a fim de se estabelecer a metodologia de maior eficiência para a área de estudo. Na primeira análise foram atribuídas notas a cada uma das informações utilizadas, de acordo com o estudo de Torres et al. (2014) para o município de Ubá (a cerca de $40 \mathrm{~km}$ da área de estudo) (Tabela 1).

Os cruzamentos também seguiram a proposta de Torres et al. (2014), na qual inicialmente foi realizado o cruzamento do uso do solo (com peso de 50\%) com a exposição das vertentes (peso de $50 \%$ ); o produto gerado (com peso de 66\%) foi cruzado com a declividade (peso $34 \%$ ) e esse resultado foi finalmente cruzado com o buffer de $15 \mathrm{~m}$ ao redor das áreas urbanizadas e vias de acesso (ambos com peso de 50\%).

As classes de risco foram distribuídas de acordo com os resultados das operações realizadas pelo software da seguinte forma: nulo (0), baixíssimo ( 0,1 a 15$)$, baixo (15,1 a 30), médio (30,1 a 40), alto (40,1 a 60$)$ e altíssimo $(>60,1)$.

Assume-se que a classe de baixíssimo risco deve compreender a maior extensão da área de estudo e que o tamanho da área abrangida por cada classe de risco deve diminuir com o aumento do risco, chegando à classe de altíssimo risco, com a menor extensão de área. Essa condição está relacionada ao fato de na maior parte da área de estudo não se ter observado a ocorrência de incêndios (classes de risco mais baixas), por outro lado, as áreas em que há a recorrência do evento (classes de risco mais altas) são restritas quando comparadas à área total, fazendo com que as classes de risco mais baixas abranjam maiores áreas em comparação com as classes de risco mais altas. Assim sendo, na segunda análise, utilizando as mesmas notas atribuídas às classes preditoras da primeira análise, as classes de risco foram distribuídas em função do tamanho de sua área da seguinte forma (Tabela 2).

$\mathrm{Na}$ terceira análise, com o intuito de se avaliar a influência do histórico de incêndios sobre as ocorrências, carregaram-se os focos sobre as informações preditoras, de forma que quanto maior o número de focos de incêndios, maior a nota atribuída, sendo essa nota variável de 0 (nenhum foco observado) a 10 (maior número de focos observados) (Tabela 3). A distribuição das classes de risco foi feita de acordo com a primeira análise.

Na quarta análise, as notas atribuídas a cada classe preditora foram as mesmas da terceira análise (Tabela 3), enquanto que as classes de risco foram distribuídas de acordo com a segunda análise (Tabela 2).

Tabela 1. Tabela de notas atribuídas à primeira análise do mapeamento de risco de incêndio florestal em Viçosa, MG.

Table 1. Table of scores assigned to the first analysis of the mapping of forest fires risk in Viçosa (MG).

\begin{tabular}{|c|c|c|c|c|c|}
\hline \multicolumn{2}{|c|}{ Uso do solo } & \multicolumn{2}{|c|}{ Exposição das vertentes } & \multicolumn{2}{|c|}{ Declividade } \\
\hline Classe & Notas & Classe & Notas & Classe & Notas \\
\hline Área nula* & 0 & $\operatorname{Sul}\left(135^{\circ}\right.$ a $\left.225^{\circ}\right)$ & 4 & $0^{\circ}$ a $10^{\circ}$ & 2 \\
\hline Mata & 3 & Leste $\left(45^{\circ}\right.$ a $\left.135^{\circ}\right)$ & 6 & $10^{\circ}$ a $20^{\circ}$ & 4 \\
\hline Agricultura & 5 & Oeste $\left(225^{\circ}\right.$ a $\left.315^{\circ}\right)$ & 8 & $20^{\circ}$ a $30^{\circ}$ & 6 \\
\hline Capoeira & 7 & Norte $\left(315^{\circ}\right.$ a $\left.45^{\circ}\right)$ & 10 & $30^{\circ}$ a $40^{\circ}$ & 8 \\
\hline Floresta plantada & 8 & & & $>40^{\circ}$ & 10 \\
\hline Pasto & 10 & & & & \\
\hline
\end{tabular}

*Área construída, solo exposto e corpos hídricos. Fonte: Adaptado de Torres et al. (2014). 


\section{RESULTADOS}

Os resultados a respeito da influência dos elementos preditores sobre as ocorrências de incêndio florestal podem ser observados na Tabela 4 .

Tabela 2. Distribuição das classes de risco de acordo com a porcentagem da área.

Table 2. Distribution of risk classes according to the percentage of the area.

\begin{tabular}{|cc|}
\hline Classe de risco & Porcentagem da área \\
\hline Nulo & - \\
\hline Baixíssimo & $38 \%$ \\
\hline Baixo & $28,5 \%$ \\
\hline Médio & $19 \%$ \\
\hline Alto & $9,5 \%$ \\
\hline Altíssimo & $5 \%$ \\
\hline
\end{tabular}

Analisando-se as quatro metodologias (Figura $2 \mathrm{e}$ Tabela 5) utilizadas para a determinação do risco de incêndios, subtraíram-se as áreas classificadas como risco nulo, o que significou uma pequena diferença ( $1,83 \mathrm{ha})$ nas áreas totais. Isso ocorreu porque nas análises 1 e 2 as notas dadas a cada classe preditora, baseadas no estudo de Torres et al. (2014), foram diferentes das aplicadas nas análises 3 e 4, que levaram em consideração o número de ocorrências por classe preditora.

\section{DISCUSSÃO}

Com relação à eficiência das quatro metodologias, deve se levar em consideração duas condições desejáveis: primeira, da tendência decrescente do tamanho da

Tabela 3. Atribuição de notas de acordo com o número de focos de cada classe preditora.

Table 3. Determination of banknotes according to the number of fires of each class predictor.

\begin{tabular}{lcclcc}
\multicolumn{1}{c}{ Classe preditora } & Focos & Nota & \multicolumn{1}{c}{ Classe preditora } & Focos & Nota \\
\hline Área nula* & 0 & 0 & Dec. de $0^{\circ}$ a $10^{\circ}$ & 2 & 3 \\
\hline Mata & 12 & 8 & Dec. de $10^{\circ}$ a $20^{\circ}$ & 23 & 8 \\
\hline Agricultura & 5 & 5 & Dec. de $20^{\circ}$ a $30^{\circ}$ & 47 & 10 \\
Capoeira & 7 & 7 & Dec. de $30^{\circ}$ a $40^{\circ}$ & 7 & 6 \\
\hline Floresta plantada & 3 & 3 & Dec. $>40^{\circ}$ & 16 & 0 \\
\hline Pasto & 52 & 10 & Prox. de 0 a $5 \mathrm{~m}$ & 9 & 6 \\
\hline Exp. sul $\left(135^{\circ} \mathrm{a} 225^{\circ}\right)$ & 5 & 4 & Prox. de 5,1 a $10 \mathrm{~m}$ & 3 & 4 \\
\hline Exp. leste $\left(45^{\circ}\right.$ a $\left.135^{\circ}\right)$ & 7 & 5 & Prox. de 10,1 a $15 \mathrm{~m}$ & 2 & 3 \\
\hline Exp. oeste $\left(225^{\circ}\right.$ a $\left.315^{\circ}\right)$ & 29 & 8 & Prox.de 15,1 a $20 \mathrm{~m}$ & 49 & 10 \\
\hline Exp. norte $\left(315^{\circ}\right.$ a $\left.45^{\circ}\right)$ & 38 & 10 & Prox. $>20$ & & \\
\hline
\end{tabular}

*Área construída, solo exposto e corpos hídricos.

Tabela 4. Porcentagem da área e número de focos por hectare das classes preditoras de incêndios florestais no município de Viçosa, MG.

Table 4. Percentage of area and number of fires per hectare of predictor classes to forest fires in Viçosa, MG.

\begin{tabular}{|c|c|c|c|c|c|}
\hline \multicolumn{3}{|c|}{ Classes relacionadas ao uso do solo } & \multicolumn{3}{|c|}{ Classes relacionadas ao meio físico } \\
\hline Classe preditora & $\%$ da área & focos/ha & Classe preditora & \% da área & focos/ha \\
\hline Área nula & $2,98 \%$ & 0 & Dec. $>40^{\circ}$ & $0,01 \%$ & 0 \\
\hline Mata & $19,77 \%$ & 0,0020434 & Dec. de $0^{\circ}$ a $10^{\circ}$ & $32,39 \%$ & 0,0002079 \\
\hline Pasto & $70,97 \%$ & 0,0024667 & Dec. de $10^{\circ}$ a $20^{\circ}$ & $47,83 \%$ & 0,0016191 \\
\hline Agricultura & $2,60 \%$ & 0,0064757 & Dec. de $20^{\circ}$ a $30^{\circ}$ & $18,67 \%$ & 0,0084763 \\
\hline Floresta plantada & $1,55 \%$ & 0,0065086 & Dec. de $30^{\circ}$ a $40^{\circ}$ & $1,11 \%$ & 0,0212805 \\
\hline Capoeira & $2,12 \%$ & 0,0111005 & Total & $100,00 \%$ & 0,0026597 \\
\hline Total & $100,00 \%$ & 0,0026597 & Classe preditora & \% da área & focos/ha \\
\hline Classe preditora & \% da área & focos/ha & Exp. sul & $22,95 \%$ & 0,0007336 \\
\hline Prox. $>20 \mathrm{~m}$ & $96,61 \%$ & 0,0017075 & Exp. leste & $23,92 \%$ & 0,0009852 \\
\hline Prox. de 15,1 a $20 \mathrm{~m}$ & $0,72 \%$ & 0,0093575 & Exp. oeste & $26,51 \%$ & 0,0036834 \\
\hline Prox. de 10,1 a $15 \mathrm{~m}$ & $0,51 \%$ & 0,0199568 & Exp. norte & $26,63 \%$ & 0,0048051 \\
\hline Prox. de 5,1 a $10 \mathrm{~m}$ & $1,26 \%$ & 0,0241179 & Total & $100,00 \%$ & 0,0026597 \\
\hline Prox. de 0 a $5 \mathrm{~m}$ & $0,90 \%$ & 0,0596348 & & & \\
\hline Total & $100,00 \%$ & 0,0026597 & & & \\
\hline
\end{tabular}




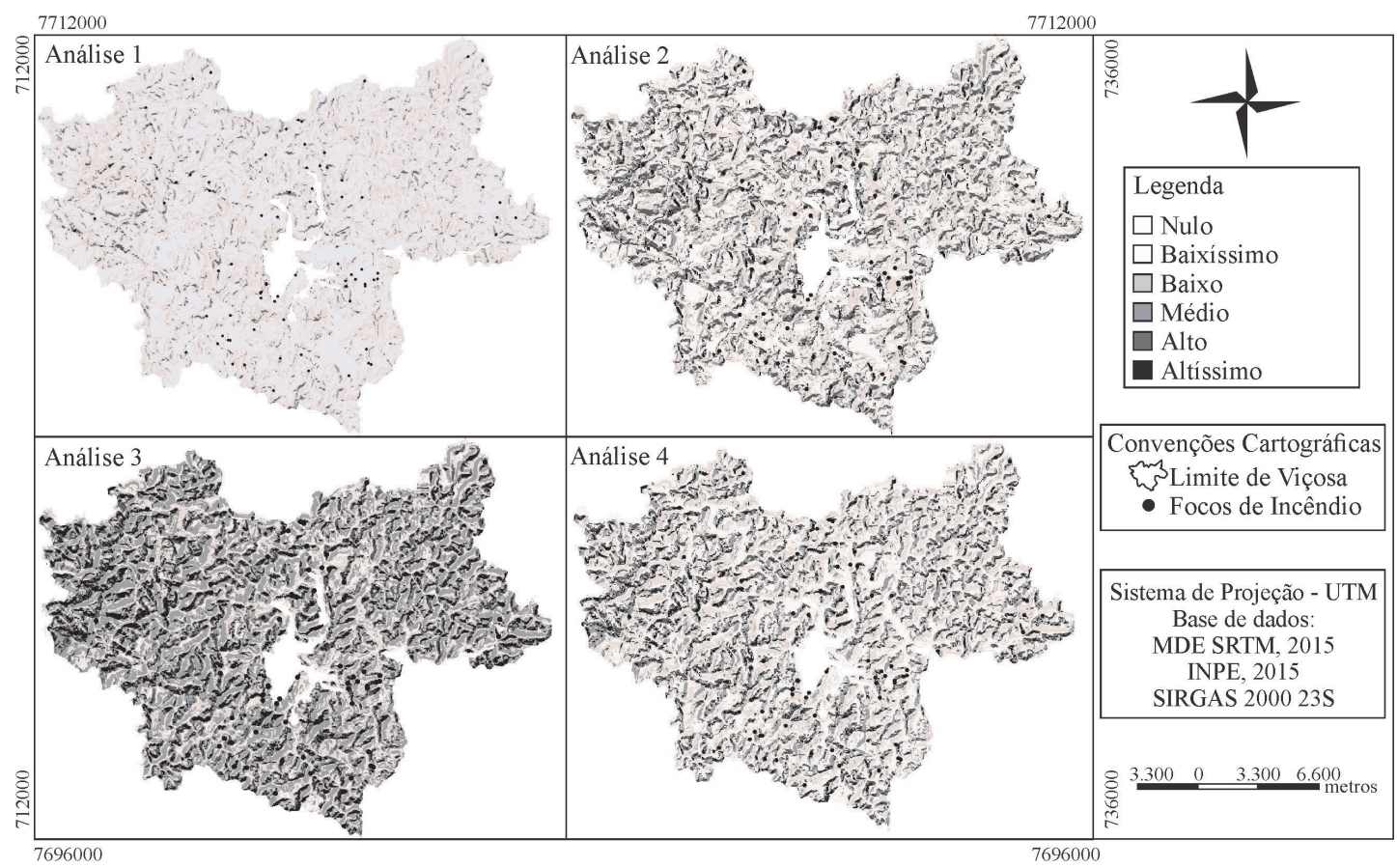

Figura 2. Mapas gerados pelas quatro metodologias utilizadas para determinação do risco de incêndios em Viçosa, MG.

Figure 2. Maps generated by the four methodologies used to determine the forest fires risk in Viçosa (MG).

área da classe baixíssimo para a classe altíssimo risco; e segunda, da distribuição crescente do número de ocorrências por classe de risco (também no sentido baixíssimo-altíssimo), em outras palavras, é desejável que as classes de menor risco tenham maior área de abrangência e menor número de ocorrências, contrapondo-se às classes de maior risco, para as quais o ideal é que tenham menor área e maior número de ocorrências. As duas condições podem ser representadas pela tendência crescente do valor número de focos por hectare (Tabela 5) das classes de risco. Apenas duas metodologias apresentaram essa tendência ( 1 e 2), contudo, os resultados apontam para a metodologia 1 como a mais eficiente, visto que apresenta o maior valor focos/hectare da classe altíssimo risco (e do somatório altíssimo + alto) e menor valor para a classe baixíssimo risco (e do somatório baixíssimo + baixo) de todas as metodologias testadas.

A utilização da nota de acordo com o número de ocorrências, em cada classe preditora (análises 3 e 4), não se mostrou tão eficiente em relação às outras metodologias, talvez pelo maior número absoluto de focos se concentrar nas classes de maior extensão dentro da área de estudo (sobretudo pasto e distância superior à $20 \mathrm{~m}$ dos equipamentos urbanos), sugerindo uma melhor adequação na forma de valoração das classes em função da quantidade de ocorrências.

Por outro lado, as notas aplicadas às classes preditoras, nas análises 1 e 2, foram as mesmas utilizadas no município de Ubá por Torres et al. (2014), o que indica serem adequadas para retratarem o peso desses fatores de risco a incêndios na região.

Apesar da eficácia da utilização de satélites na detecção de incêndios florestais (Barlow et al., 2012), os altos níveis de cobertura de nuvens acima de florestas tropicais úmidas muitas vezes complicam os resultados, pois fogo de sub-bosque permanece difícil de detectar a partir das imagens e, ainda, é muito difícil mapear pequenos incêndios em paisagens fragmentadas.

Por outro lado, na China, o número de incêndios detectados por satélites foi maior do que o número de incêndios florestais, de acordo com as estatísticas obtidas do governo, o que corresponde a 136\% (faixa variável 84-177\%) do número de incêndios florestais no período 2008-2012 (Tian et al., 2013). 
Tabela 5. Número de ocorrências e tamanho das áreas por classes de risco em Viçosa, MG.

Table 5. Number of occurrences and size of the areas by risk classes in Viçosa, MG.

\begin{tabular}{|c|c|c|c|c|c|}
\hline \multicolumn{6}{|c|}{ 1 a Análise } \\
\hline \multirow{2}{*}{ Classe de risco } & \multicolumn{2}{|c|}{ Focos } & \multicolumn{2}{|c|}{ Tamanho da área } & \multirow{2}{*}{ Focos/ hectare } \\
\hline & $\mathrm{N}^{\circ}$ & $\%$ & ha & $\%$ & \\
\hline Baixíssimo & 2 & $2,53 \%$ & $16.534,36$ & $57,39 \%$ & 0,000121 \\
\hline Baixo & 4 & $5,06 \%$ & $10.352,57$ & $35,93 \%$ & 0,000386 \\
\hline Médio & 14 & $17,72 \%$ & $1.136,19$ & $3,94 \%$ & 0,012322 \\
\hline Alto & 36 & $45,57 \%$ & 767,43 & $2,66 \%$ & 0,046910 \\
\hline Altíssimo & 23 & $29,11 \%$ & 19,46 & $0,07 \%$ & 1,181912 \\
\hline TOTAL & 79 & $100 \%$ & $28.810,02$ & $100 \%$ & 0,002742 \\
\hline \multicolumn{6}{|c|}{$2^{\mathrm{a}}$ Análise } \\
\hline \multirow{2}{*}{ Classe de risco } & \multicolumn{2}{|c|}{ Focos } & \multicolumn{2}{|c|}{ Tamanho da área } & \multirow{2}{*}{ Focos/ hectare } \\
\hline & $\mathbf{N}^{\circ}$ & $\%$ & ha & $\%$ & \\
\hline Baixíssimo & 2 & $2,53 \%$ & $10.967,84$ & $38 \%$ & 0,000182 \\
\hline Baixo & 3 & $3,80 \%$ & $7.956,01$ & $28,5 \%$ & 0,000377 \\
\hline Médio & 6 & $7,59 \%$ & $5.418,58$ & $19 \%$ & 0,001107 \\
\hline Alto & 18 & $22,78 \%$ & $3.117,46$ & $9,5 \%$ & 0,005774 \\
\hline Altíssimo & 50 & $63,29 \%$ & $1.350,12$ & $5 \%$ & 0,037034 \\
\hline TOTAL & 79 & $100 \%$ & $28.810,02$ & $100 \%$ & 0,002742 \\
\hline \multicolumn{6}{|c|}{$3^{\mathrm{a}}$ Análise } \\
\hline \multirow{2}{*}{ Classe de risco } & \multicolumn{2}{|c|}{ Focos } & \multicolumn{2}{|c|}{ Tamanho da área } & \multirow{2}{*}{ Focos/ hectare } \\
\hline & No & $\%$ & ha & $\%$ & \\
\hline Baixíssimo & 1 & $1,27 \%$ & $2.778,81$ & $9,64 \%$ & 0,000360 \\
\hline Baixo & 2 & $2,53 \%$ & $6.017,78$ & $20,89 \%$ & 0,000332 \\
\hline Médio & 32 & $40,51 \%$ & $11.648,91$ & $40,43 \%$ & 0,002747 \\
\hline Alto & 8 & $10,13 \%$ & $3.955,57$ & $13,73 \%$ & 0,002022 \\
\hline Altíssimo & 36 & $45,57 \%$ & $4.410,78$ & $15,31 \%$ & 0,008162 \\
\hline TOTAL & 79 & $100 \%$ & $28.811,85$ & $100 \%$ & 0,002742 \\
\hline \multicolumn{6}{|c|}{$4^{\mathrm{a}}$ Análise } \\
\hline \multirow{2}{*}{ Classe de risco } & \multicolumn{2}{|c|}{ Focos } & \multicolumn{2}{|c|}{ Tamanho da área } & \multirow{2}{*}{ Focos/ hectare } \\
\hline & No & $\%$ & ha & $\%$ & \\
\hline Baixíssimo & 5 & $6,33 \%$ & $10.985,83$ & $38 \%$ & 0,000455 \\
\hline Baixo & 16 & $20,25 \%$ & $7.811,10$ & $28,5 \%$ & 0,002048 \\
\hline Médio & 19 & $24,05 \%$ & $5.570,92$ & $19 \%$ & 0,003411 \\
\hline Alto & 8 & $10,13 \%$ & $2.434,10$ & $9,5 \%$ & 0,003287 \\
\hline Altíssimo & 31 & $39,24 \%$ & $2.009,90$ & $5 \%$ & 0,015424 \\
\hline TOTAL & 79 & $100 \%$ & $28.811,85$ & $100 \%$ & 0,002742 \\
\hline
\end{tabular}

Para os satélites utilizados pelo INPE, trabalhos de validação de campo indicam que uma frente de fogo com cerca de $30 \mathrm{~m}$ de extensão por $1 \mathrm{~m}$ de largura, ou maior, será detectada (Abreu \& Souza, 2016), sendo essa então a dimensão mínima das ocorrências analisadas neste estudo.

Em Viçosa, no período de 1/1/2010 a 31/12/2014, o Corpo de Bombeiros registrou 147 ocorrências, enquanto apenas 60 focos foram observados pelos satélites. Contudo, devido à falta de consistência do registro de ocorrências, optou-se pela utilização dos focos, pois apesar do menor número de registros, seu posicionamento espacial é mais confiável.

O risco de incêndios florestais é produto dos vários fatores conhecidos por afetar o comportamento do fogo: ignição, topografia, vegetação e as condições meteorológicas (Paz et al., 2011). Estes autores, em uma análise do peso dos fatores específicos na determinação do mapa de risco na região de Monte Carmel (Israel), concluíram que nenhum fator isolado pode explicar o 
padrão geral do mapa de risco. Todos esses parâmetros foram quase igualmente importantes na influência do padrão de risco.

O mesmo foi observado no município de Viçosa, para o qual nenhuma das classes preditoras isoladamente explicou a distribuição das ocorrências, o que ajuda a esclarecer o porquê de as análises - cujas notas das classes preditoras foram em função do número de ocorrências (3 e 4) - apresentarem menor eficiência. Todavia, este estudo conseguiu retratar a influência dos fatores relevo, clima e uso do solo sobre a ocorrência de incêndios florestais.

Com relação ao relevo, observa-se na Tabela 4 que quanto maior a declividade, maior a susceptibilidade às ocorrências, com exceção da classe acima de $40^{\circ}$, visto que áreas nessa situação são muito restritas no município (apenas 2,3 ha), contudo, salienta-se que esses valores são em função das limitações da base de dados disponíveis para este estudo, podendo haver distorções por conta da escala, sobretudo em áreas de menor extensão. Adámek et al. (2015) mencionam que em regiões onde o clima é mais úmido existe a tendência de a irregularidade do relevo favorecer a ocorrência de incêndios. Por outro lado, segundo os mesmos autores, nas regiões onde o clima é seco, quando a paisagem é predominantemente plana, os incêndios são mais frequentes do que nas áreas irregulares, visto que as barreiras que limitam a propagação do fogo não são frequentes e a distribuição de combustível é contínua.

Para Ganteaume \& Jappiot (2013), vários estudos mostram que a probabilidade de ocorrência de grandes incêndios é maior em áreas de alta rugosidade topográfica, que podem facilitar a ocorrência e propagação do fogo e limitam o acesso para o combate.

Além do aspecto topográfico, a exposição das vertentes ao sol também mostra o controle climático sobre as ocorrências. Devido à latitude da área de estudo, vertentes com exposição norte são mais quentes e secas, seguidas em ordem decrescente pelas vertentes oeste, leste e sul (Torres et al., 2014).

Destaca-se que a grande influência do clima está no seu controle sobre o tipo de vegetação e seu teor de umidade. Ganteaume \& Jappiot (2013) observaram que, no sul da França, apesar de alguns estudos na Europa mostrarem que a cobertura vegetal não é um fator primordial (em comparação com o clima) sobre as ocorrências, ou que pequenos incêndios são mais influenciados pelo uso do solo do que grandes incêndios, a vegetação herbácea, por ser mais influenciada pelas condições atmosféricas reinantes em um dado momento, apresentou maiores valores tanto no número de incêndios quanto no tamanho das áreas queimadas.

Na Colômbia, Armenteras-Pascual et al. (2011), comparando o tamanho da área queimada de acordo com a vegetação, mostraram que a vegetação campestre foi o tipo mais queimado, seguido por capoeiras, florestas e áreas agrícolas. O padrão para o número de ocorrências foi bastante diferente, contudo a vegetação campestre novamente mostrou o valor mais alto, seguida de perto por zonas agrícolas, florestas e capoeiras.

Por outro lado, de acordo com Gralewicz et al. (2012), no Canadá, 55,15\% da área queimada é coberta por florestas de coníferas e apenas um pequeno número de incêndios ocorre nas fisionomias campestres, sendo esses tipicamente danos colaterais de incêndios florestais.

Em Viçosa, analisando-se os dados da Tabela 4, os resultados são mascarados pelo número de ocorrências e tamanho da área coberta por pastos na região, apesar de concentrar $66 \%$ do número de incêndios, a classe compreende $71 \%$ da área de estudo.

Na Galícia (Espanha), Fuentes-Santos et al. (2013) concluíram que a análise das interações espaço-temporais entre incêndios florestais (testadas para diferentes períodos do ano) revelou a ausência de dependência espacial entre os anos, ou seja, a identificação de localização de incêndio em um ano não é um preditor confiável de localização para anos seguintes. Contudo, em Viçosa, o grande número de focos/ha obtido pela capoeira mostra que perturbações recorrentes são observadas nesses locais, resultado semelhante ao encontrado por Vázquez \& Moreno (2001) em Sierra de Gredos, também na Espanha.

Independentemente do relevo, das condições climáticas ou da vegetação, a fonte de ignição de origem antrópica não é homogênea em todo o globo. As pessoas interferem nos ciclos anuais do fogo em muitas partes do mundo, diminuindo ou aumentando as épocas e áreas mais propícias à ocorrência de fogo. A intervenção humana afeta, portanto, o início do evento, exercendo um controle importante da atividade do fogo além de suas limitações "naturais", mascarando a influência do clima (Bedia et al., 2015).

Em Viçosa observou-se que há uma diminuição das ocorrências à medida que nos afastamos dos eixos 
das estradas e das áreas urbanas, havendo, a partir de determinada distância, um novo aumento (Tabela 3). O mesmo foi observado na China por Tian et al. (2013). Para os autores, uma das razões desse fenômeno é que há um nível muito mais elevado de atividade humana e mais fontes de ignição em torno dos equipamentos urbanos, por outro lado, fogo longe desses equipamentos é improvável que seja detectado pela população local, além de apresentar maior dificuldade do acesso para o combate, o que facilitando sua propagação em uma área remota com combustível abundante.

Nesse contexto, o estudo de Zumbrunnen et al. (2011) demonstra o caráter não linear da relação entre ocorrência de incêndios e densidade populacional e de estradas, em particular o nivelamento de ocorrência de incêndios quando potenciais fontes de ignição antrópicas aumentam. Portanto, os aumentos previstos no número de habitantes e a expansão associada de áreas urbanizadas e cobertura de estradas podem não resultar em mais incêndios, exceto se esse aumento da população ocorre em áreas menos habitadas.

É amplamente reconhecido que quanto mais se entender sobre o comportamento do fogo e sua resposta às condições ambientais mais se poderão antecipar situações perigosas ou impactos de grande magnitude e mais acertadas serão as decisões sobre a gestão de combustíveis e dos incêndios (Linn et al., 2012). Diante disso, novos estudos em diferentes regiões fornecerão importantes informações que amenizarão os efeitos deletérios dos incêndios florestais.

\section{CONCLUSÕES}

De acordo com os resultados, concluiu-se que:

- Nenhum fator isolado pode explicar o padrão geral do risco de incêndio na região de Viçosa, MG;

- Apesar de reconhecidamente ser a cobertura vegetal mais propensa à ocorrência de incêndios, o tamanho da área coberta por vegetação herbácea (pasto) mascarou os resultados;

- A maior densidade de focos em áreas de capoeira mostra a possibilidade de eventos recorrentes nesses locais;
- Áreas com maior ganho energético solar, como as vertentes voltadas para o norte, apresentaram maior número de ocorrências, mostrando que apesar da influência antrópica, o clima exerce significativo controle sobre os incêndios;

- Quanto maior a inclinação do terreno, maior a probabilidade de ocorrências;

- O número de ocorrências diminui conforme a distância dos equipamentos urbanos e volta a aumentar depois de certa distância mostrando a influência antrópica sobre o início do evento;

- A metodologia 1 utilizada se mostrou eficiente para o mapeamento do risco de incêndios na região, contudo torna-se necessária a confecção de mapas em outras áreas para melhor aferir sua eficiência.

\section{STATUS DA SUBMISSÃO}

Recebido: 25 abr., 2016

Aceito: dia 21 jun., 2016

\section{AUTOR(ES) PARA CORRESPONDÊNCIA}

\section{Fillipe Tamiozzo Pereira Torres}

Universidade Federal de Viçosa - UFV, Avenida P. H. Rolfs, s/n, Campus UFV, CEP 36570-000, Viçosa, MG, Brasil

e-mail: torresftp2@gmail.com

\section{REFERÊNCIAS}

Abreu FA, Souza JSA. Dinâmica espaço-temporal de focos de calor em duas terras indígenas do Estado de Mato Grosso: uma abordagem geoespacial sobre a dinâmica do uso do fogo por Xavantes e Bororos. Floresta e Ambiente 2016; 23(1): 1-10. http://dx.doi.org/10.1590/2179-8087.041813.

Adámek M, Bobek P, Hadincová V, Wild J, Kopecký M. Forest fires within a temperate landscape: a decadal and millennial perspective from a sandstone region in Central Europe. Forest Ecology and Management 2015; 2015(336): 81-90. http://dx.doi.org/10.1016/j.foreco.2014.10.014.

Armenteras-Pascual D, Retana-Alumbreros J, MolownyHoras R, Roman-Cuesta RM, Gonzalez-Alonso F, MoralesRivas M. Characterising fire spatial pattern interactions with climate and vegetation in Colombia. Agricultural and Forest Meteorology 2011; 2011(151): 279-289. http:// dx.doi.org/10.1016/j.agrformet.2010.11.002. 
Barlow J, Parry L, Gardner TA, Ferreira J, Aragão LEOC, Carmenta $\mathrm{R}$ et al. The critical importance of considering fire in REDD+ programs. Biological Conservation 2012; 2012(154): 1-8. http://dx.doi.org/10.1016/j.biocon.2012.03.034.

Bedia J, Herrera S, Gutiérrez JM, Benali A, Brands S, Mota $B$ et al. Global patterns in the sensitivity of burned area to fire-weather: implications for climate change. Agricultural and Forest Meteorology 2015; 214-215: 369-379. http:// dx.doi.org/10.1016/j.agrformet.2015.09.002.

Borges TS, Fiedler NC, Santos AR, Loureiro EB, Mafia RG. Desempenho de alguns índices de risco de incêndios em plantios de eucalipto no norte do Espírito Santo. Floresta e Ambiente 2011; 18(2): 153-159. http://dx.doi. org/10.4322/floram.2011.033.

Chang Y, Zhu Z, Bu R, Li Y, Hu Y. Environmental controls on the characteristics of mean number of forest fires and mean forest area burned (1987-2007) in China. Forest Ecology and Management 2015; 2015(356): 13-21. PMid:26288802. http://dx.doi.org/10.1016/j.foreco.2015.07.012.

Costa TA, Soares VP, Ribeiro CAAS, Gleriani JM. Conflitos de uso da terra na microbacia do São Bartolomeu - Viçosa, MG. Floresta e Ambiente 2013; 20(3): 281-295.

Fernandes MC, Coura PHF, Sousa GM, Avelar AS. Avaliação geoecológica de susceptibilidade à ocorrência de incêndios no estado do Rio de Janeiro, Brasil. Floresta e Ambiente 2011; 18(3): 299-309. http://dx.doi.org/10.4322/ floram.2011.050.

Ferreira AJD, Alegre SP, Coelho COA, Shakesby RA, Páscoa FM, Ferreira CSS et al. Strategies to prevent forest fires and techniques to reverse degradation processes in burned areas. Catena 2015; 2015(128): 224-237. http:// dx.doi.org/10.1016/j.catena.2014.09.002.

Fuentes-Santos I, Marey-Pérez MF, González-Manteiga W. Forest fire spatial pattern analysis in Galicia (NW Spain). Journal of Environmental Management 2013; 2013(128): 30-42. PMid:23714585. http://dx.doi.org/10.1016/j. jenvman.2013.04.020.

Ganteaume A, Jappiot M. What causes large fires in Southern France. Forest Ecology and Management 2013; 2013(294): 76-85. http://dx.doi.org/10.1016/j.foreco.2012.06.055.

Gralewicz NJ, Nelson TA, Wulder MA. Factors influencing national scale wildfire susceptibility in Canada. Forest Ecology and Management 2012; 2012(265): 20-29. http:// dx.doi.org/10.1016/j.foreco.2011.10.031.

Herawati H, Santoso H. Tropical forest susceptibility to and risk of fire under changing climate: a review of fire nature, policy and institutions in Indonesia. Forest Policy and Economics 2011; 2011(13): 227-233. http://dx.doi. org/10.1016/j.forpol.2011.02.006.

Instituto Nacional de Pesquisas Espaciais - INPE. Portal do monitoramento de queimadas e incêndios [online]. Brasília; 2015 [citado em 2015 jun 18]. Disponível em: http://www.inpe.br/queimadas
Linn RR, Canfield JM, Cunningham P, Edminster C, Dupuy JL, Pimont F. Using periodic line fires to gain a new perspective on multi-dimensional aspects of forward fire spread. Agricultural and Forest Meteorology 2012; 2012(157): 60-76. http://dx.doi.org/10.1016/j.agrformet.2012.01.014.

Miranda A No, Martins SV, Silva KA, Gleriani JM. Relações Ecológicas entre Estratos de uma Área Restaurada, com 40 anos, Viçosa-MG. Floresta e Ambiente 2012; 19(4): 393-404. http://dx.doi.org/10.4322/floram.2012.050.

National Aeronautics and Space Administration - NASA. Shuttle radar topography mission [online]. 2010. [citado em 2010 maio 19]. Disponível em: http://www2.jpl.nasa. gov/srtm/

Paz S, Carmel Y, Jahshan F, Shoshany M. Post-fire analysis of pre-fire mapping of fire-risk: a recent case study from Mt. Carmel (Israel). Forest Ecology and Management 2011; 2011(262): 1184-1188. http://dx.doi.org/10.1016/j. foreco.2011.06.011.

Pezzopane JEM, Oliveira SN No, Vilela MF. Risco de incêndios em função da característica do clima, relevo e cobertura do solo. Floresta e Ambiente 2001; 8(1): 161-166.

Tian X, Zhao F, Shu L, Wang M. Distribution characteristics and the influence factors of forest fires in China. Forest Ecology and Management 2013;2013(310): 460-467. http:// dx.doi.org/10.1016/j.foreco.2013.08.025.

Torres FTP, Ribeiro GA, Martins SV, Lima GS. Mapeamento da suscetibilidade a ocorrências de incêndios em vegetação na área urbana de Ubá-MG. Árvore 2014; 38(5): 811-817. http://dx.doi.org/10.1590/S0100-67622014000500005.

Vakalis D, Sarimveis H, Kiranoudis CT, Alexandridis A, Bafas G. A GIS based operational system for wildland fire crisis management II. System architecture and case studies. Applied Mathematical Modelling 2004; 28(4): 411-425. http://dx.doi.org/10.1016/j.apm.2003.10.006.

Vázquez A, Moreno JM. Spatial distribution of forest fires in Sierra de Gredos (Central Spain). Forest Ecology and Management 2001; 147(1): 55-65. http://dx.doi. org/10.1016/S0378-1127(00)00436-9.

Vijayakumar DBIP, Raulier F, Bernier PY, Gauthier S, Bergeron Y, Pothier D. Lengthening the historical records of fire history over large areas of boreal forest in eastern Canada using empirical relationships. Forest Ecology and Management 2015; 2015(347): 30-39. http://dx.doi. org/10.1016/j.foreco.2015.03.011.

Yang J, Healy HS, Shifley SR, Gustafson EJ. Spatial patterns of modern period human-caused fire occurrence in the Missouri Ozark Highlands. Forest Science 2007; 53(1): 1-15.

Zumbrunnen T, Pezzatti GB, Menéndez P, Bugmann $\mathrm{H}$, Bürgi M, Conedera M. Weather and human impacts on forest fires: 100 years of fire history in two climatic regions of Switzerland. Forest Ecology and Management 2011; 2011(261): 2188-2199. http://dx.doi.org/10.1016/j. foreco.2010.10.009. 